\title{
Sensibilidad antibiótica de bacterias obtenidas de queratitis e infecciones intraoculares en la Fundación Oftalmológica de Santander (FOSCAL), Floridablanca, Colombia
}

\author{
Virgilio Galvis ${ }^{1,2}$, Alejandro Tello ${ }^{1,2}$, Alfredo Guerra ${ }^{3}$, María Fernanda Acuña ${ }^{1}$, Donaldo Villarreal ${ }^{4}$ \\ 1 Centro Oftalmológico Virgilio Galvis, Floridablanca, Colombia \\ 2 Departamento de Cirugía, Escuela de Medicina, Facultad de Salud, Universidad Autónoma de Bucaramanga, \\ Bucaramanga, Colombia \\ ${ }^{3}$ Departamento de Oftalmología, Fundación Oftalmológica de Santander (FOSCAL), Floridablanca, Colombia \\ ${ }^{4}$ Laboratorio Clínico Higuera Escalante-Centro de Diagnóstico Ocular (OCULAB), Floridablanca, Colombia
}

Introducción. La resistencia bacteriana es crítica para la selección de los antibióticos en el tratamiento de las infecciones, por ello es vital conocer su estado actual en nuestro medio.

Objetivo. Determinar la sensibilidad antibiótica bacteriana in vitro obtenida de los cultivos de queratitis e infecciones intraoculares.

Materiales y métodos. Se llevó a cabo un estudio retrospectivo en la Fundación Oftalmológica de Santander (FOSCAL), entre junio de 2011 y enero de 2012.

Resultados. Se examinaron 92 muestras. Se identificaron 110 bacterias, 27 hongos y 12 amebas de vida libre. Del total de bacterias Gram positivas, $1,1 \%, 0 \%, 1,1 \%, 16,9 \%, 29,3 \%$ y $85 \%$ fue resistente a imipenem, moxifloxacina, gatifloxacina, levofloxacina, ciprofloxacina y tobramicina, respectivamente, mientras que la resistencia a estos mismos fármacos se presentó, respectivamente, en $0 \%, 8,3 \%, 0 \%, 0 \%, 18,2 \%$ y $27,3 \%$ de las bacterias Gram negativas. Los porcentajes de resistencia de los estafilococos positivos para coagulasa resistentes a la meticilina fueron $0 \%, 0 \%, 0 \%$, $7 \%, 17 \%$ y $100 \%$, respectivamente, y los porcentajes de los estafilococos negativos para coagulasa resistentes a la meticilina fueron $3 \%, 0 \%, 0 \%, 24 \%, 44 \%$ y $100 \%$, respectivamente. Los porcentajes de resistencia bacteriana globales (tanto para bacterias Gram positivas como para Gram negativas) a imipenem, moxifloxacina, gatifloxacina, levofloxacina, ciprofloxacina y tobramicina fueron $1 \%, 1 \%$, $1 \%, 15,1 \%, 28 \%$ y $64,5 \%$, respectivamente.

Conclusiones. Los niveles de resistencia bacteriana para imipenem, moxifloxacina y gatifloxacina fueron menores que para levofloxacina, ciprofloxacina y tobramicina. Los niveles de resistencia para la tobramicina fueron muy altos, lo que pone en duda su utilidad clínica en las infecciones oculares en nuestro medio.

Palabras clave: bacterias, farmacorresistencia microbiana, antibacterianos, infecciones del ojo, queratitis, endoftalmitis.

doi: http://dx.doi.org/10.7705/biomedica.v34i0.1636

\section{Antibiotic susceptibility patterns of bacteria isolated from keratitis and intraocular infections at Fundación Oftalmológica de Santander (FOSCAL), Floridablanca, Colombia}

Introduction: Bacterial resistance is critical for the selection of antibiotics in the treatment of infections, so it is vital to know its current status in our geographical area.

Objective: To determine in vitro antibiotic susceptibility of bacterial isolates obtained from keratitis and intraocular infections.

Materials and methods: A retrospective study of microbiological tests in Fundación Oftalmológica de Santander (FOSCAL) was carried out between June, 2011, and January, 2012.

Results: A total of 92 samples were examined and 110 bacteria, 27 fungi and 12 free-living amoebae were identified. Polymicrobial infections constituted $50 \%$ of the total; $1.1 \%, 0 \%, 1.1 \%, 16.9 \%, 29.3 \%$ and $85 \%$ of Gram-positive bacteria were resistant to imipenem, moxifloxacin, gatifloxacin, levofloxacin, ciprofloxacin and tobramycin, respectively, while $0 \%, 8.3 \%, 0 \%, 0 \%, 18.2 \%$ and $27.3 \%$ of Gramnegative bacteria were resistant to imipenem, moxifloxacin, gatifloxacin, levofloxacin, ciprofloxacin

\footnotetext{
Contribución de los autores:

Virgilio Galvis, Alejandro Tello, Alfredo Guerra y Donaldo Villarreal: planeación y diseño del estudio.

Alfredo Guerra, María Fernanda Acuña y Donaldo Villarreal: recolección de datos.

Virgilio Galvis, Alejandro Tello, Alfredo Guerra y María Fernanda Acuña: revisión de la literatura.

Alejandro Tello, Alfredo Guerra y María Fernanda Acuña: redacción del artículo.

Todos los autores participaron en el análisis de los datos y la revisión crítica del artículo.
} 
and tobramycin, respectively. For methicillin-resistant coagulase-positive staphylococci, resistance percentages to imipenem, moxifloxacin, gatifloxacin, levofloxacin, ciprofloxacin and tobramycin were $0 \%, 0 \%, 0 \%, 7 \%, 17 \%$ and $100 \%$, respectively. For methicillin-resistant coagulase-negative staphylococci, resistance percentages to imipenem, moxifloxacin, gatifloxacin, levofloxacin, ciprofloxacin and tobramycin were $3 \%, 0 \%, 0 \%, 24 \%, 44 \%$ and $100 \%$, respectively. Overall bacterial resistance to imipenem, moxifloxacin, gatifloxacin, levofloxacin, ciprofloxacin and tobramycin, for both Gram-positive and Gram-negative, was $1 \%, 1 \%, 1 \%, 15.1 \%, 28 \%$ and $64.5 \%$, respectively.

Conclusions: The levels of bacterial resistance to imipenem, moxifloxacin and gatifloxacin were lower than for levofloxacin, ciprofloxacin and tobramycin. The levels of resistance to tobramycin were very high, which calls into question its usefulness in this region of our country.

Key words: Bacteria; drug resistance, microbial; anti-bacterial agents, antibiotics, eye infections, keratitis, endophthalmitis.

doi: http://dx.doi.org/10.7705/biomedica.v34i0.1636

El uso muy difundido, y muchas veces inapropiado, de los antibióticos en muchas partes del mundo (tanto en medicina humana como veterinaria) ha llevado a que ocurra el fenómeno de "presión selectiva" sobre las bacterias, es decir, las cepas que adquieren resistencia sobreviven y se reproducen, incrementándose así el porcentaje de microorganismos resistentes $(1,2)$.

Así como en diversas poblaciones los microorganismos han estado expuestos a diferentes cantidades de antimicrobianos, también su capacidad de resistencia a tales antimicrobianos es variable (1).

Las infecciones más comunes en la práctica oftalmológica son las conjuntivitis, las cuales, en general, no tienen consecuencias serias. Por otra parte, algunas infecciones menos comunes, como la queratitis o la endoftalmitis, pueden causar pérdida visual importante. Dado que la determinación del agente causal de una infección de este tipo puede tomar de 24 a 48 horas, por lo general se inicia un manejo empírico con antibióticos de amplio espectro, comúnmente fluoroquinolonas de cuarta generación como la gatifloxacina o la moxifloxacina (3).

En los últimos 10 años se han descrito microorganismos aislados de infecciones oculares resistentes a las fluoroquinolonas de cuarta generación (moxifloxacina y gatifloxacina) (4-6). Ante el fenómeno, algunos investigadores en diversas partes del mundo han sugerido que otros antibióticos como los aminoglucósidos podrían ser una mejor opción para el tratamiento empírico o para la profilaxis en oftalmología (6). Así, pues, realizamos este

\section{Correspondencia:}

Alejandro Tello, Centro Oftalmológico Virgilio Galvis, Centro Médico Ardila Lülle, piso 3, modulo 7, Floridablanca, Santander Teléfono: (57) 639 2929; fax: (57) 6392626

alejandrotello@gmail.com

Recibido: 07/05/13; aceptado: 13/08/13 estudio con el fin de obtener datos actualizados del patrón de resistencia a los antimicrobianos de las bacterias causales de infecciones oculares en nuestro medio.

\section{Materiales y métodos}

Se llevó a cabo un estudio descriptivo retrospectivo de una serie de registros de cultivos de muestras procedentes de la córnea o de fluidos intraoculares de pacientes del Centro Oftalmológico Virgilio Galvis y la Fundación Oftalmológica de Santander, FOSCAL, procesados en el Laboratorio Higuera Escalante-FOSCAL de Floridablanca, Santander, entre junio de 2011 y enero de 2012.

Para la toma de muestras de córnea, se practicó un raspado con pinza de relojero y se tomaron restos de tejido en la zona comprometida. En un caso, se estudió el tejido corneal obtenido en cirugía al realizarse queratoplastia penetrante (botón corneal). Para los líquidos intraoculares, la toma se realizó por punción vítrea (humor vítreo) o por paracentesis (humor acuoso).

Inicialmente, las muestras se sembraron en cuatro o cinco frascos con caldo de triptosa. En las primeras 12 horas se tomó una muestra de uno de los frascos de caldo con pipeta de Pasteur para el examen directo de detección de hongos y amebas de vida libre (blanco de calcoflúor y azul de Evans con hidróxido de potasio) y de otro frasco de caldo se tomó la muestra para la tinción de Gram.

Una vez identificadas las bacterias, en un segundo paso se realizó una siembra con asa bacteriológica en agar sangre en base Columbia y chocolate.

En cada agar se identificaron con estereomicroscopio los tipos de colonias, se hizo una nueva tinción de Gram a cada tipo de colonia, y se resembró en agar sangre, y en algunos casos también en agar manitol salado y agar feniletilalcohol si se 
identificaba una bacteria Gram positiva, o en agar MacConkey y agar sangre si se identificaba una bacteria Gram negativa. Se diferenciaron las colonias de las bacterias Gram positivas en Staphylococcus spp., Streptococcus spp., corinebacterias no filamentosas, corineformes aerobias filamentosas y bacilos Gram positivos esporulados. Según esta clasificación, se realizaron resiembras y pruebas de identificación de especies con el fin de identificar estafilococos positivos y negativos para coagulasa. Cuando se obtuvieron bacterias Gram negativas se purificó cada cepa y se hizo su identificación precisa en el analizador automatizado Vitek ${ }^{\text {TM }}$ (bioMérieux, Marcy l'Etoile, Francia).

Para el antibiograma, se tomó una muestra del cultivo sobre el agar, se sembró nuevamente en agar Mueller-Hinton (con $20 \%$ de cloruro de sodio en caso de especies de Staphylococcus) y se colocaron los discos impregnados de antibiótico (BBL Sensi-Disc Susceptibility Test Discs ${ }^{\mathrm{TM}}$, Becton Dickinson Franklin Lakes, USA) específicos para bacterias Gram positivas o Gram negativas (método de Kirby Bauer). Los sensidiscos tenían concentraciones determinadas de las sustancias estudiadas: imipenem, moxifloxacina, gatifloxacina, levofloxacina, ciprofloxacina y tobramicina.

Los antibiogramas se interpretaron con la metodología convencional de difusión en agar MuellerHinton de acuerdo con los protocolos del Clinical Laboratory Standars Institute de los Estados Unidos (7). Se incubaron las placas de agar durante 24 horas a $35^{\circ} \mathrm{C}$ y se estudió el crecimiento bacteriano en ellas.

Se valoró el diámetro de la zona de inhibición que se formó alrededor de cada disco. Con esta referencia se informó si el microorganismo era sensible (S), tenía sensibilidad intermedia (I) o era resistente $(R)$ a cada uno de los antibióticos ensayados en las placas. Un reporte de "sensible" indicaba que el patógeno muy probablemente era inhibido por los niveles sanguíneos generalmente alcanzados luego de la administración sistémica del antibiótico. Un reporte de "sensibilidad intermedia" indicaba que el microorganismo podía ser sensible si se usaban altas dosis o el sitio de la infección estaba confinado a tejidos y fluidos en los cuales se obtuvieran altos niveles de antimicrobiano. Un reporte de "resistente" indicaba que con las concentraciones séricas que se podían alcanzar in vivo era muy poco probable que hubiera un efecto inhibitorio y por ello se debía seleccionar otra opción terapéutica.
Las variables se tomaron con una ficha de recolección individual para cada muestra siguiendo las normas de la Declaración de Helsinki y luego se registraron en una base de datos en Microsoft Excel ${ }^{T \text { M. }}$.

\section{Resultados}

Se examinaron 92 muestras: 74 procedentes de úlceras corneales, 10 de humor acuoso, siete de humor vítreo y una procedente de un botón corneal. En $100 \%$ de los casos hubo crecimiento de algún microorganismo. Se identificaron 149 microorganismos: 110 bacterias $(89,1 \%$ Gram positivas y $10,9 \%$ Gram negativas); 27 hongos y 12 amebas de vida libre (cuadro 1). En el $46 \%$ del total de las muestras se aisló una sola bacteria $y$ en el $4 \%$ un solo hongo. Las infecciones polimicrobianas constituyeron el $50 \%$ del total $(16 \%$ con dos bacterias; $21 \%$ con una o dos bacterias y hongos; $13 \%$ con amebas de vida libre y bacterias u hongos) (cuadro 2).

Al analizar la sensibilidad de las bacterias a los antimicrobianos en lo que respecta al grupo total de bacterias Gram positivas y Gram negativas, los porcentajes de resistencia, en orden descendente, fueron mayores para tobramicina $(64,5 \%)$, ciprofloxacina (28\%) y levofloxacina $(15,1 \%)$ que para imipenem (1\%), moxifloxacina (1\%) y gatifloxacina (1\%) (cuadro 3).

Los datos de sensibilidad y resistencia a los antimicrobianos de las bacterias Gram positivas, Gram negativas, los estafilococos negativos para coagulasa y resistentes a meticilina, los estafilococos negativos para coagulasa y sensibles a meticilina, los estafilococos positivos para coagulasa y resistentes a meticilina, los estafilococos positivos para coagulasa y sensibles a meticilina, los Streptococcus spp. grupo alfa hemolítico y las colonias de Pseudomonas aeruginosa, discriminados por cepas bacterianas, se encuentran en los cuadros 4 a 10.

\section{Discusión}

Durante millones de años, las bacterias han evolucionado de manera paralela con sus huéspedes, y antes de la era de los antibióticos, se habían ido adaptando gradualmente a sus sistemas de defensa naturales, ganando eficacia como agentes infecciosos. El descubrimiento de los antibióticos durante el siglo XX permitió que las enfermedades causadas por estos microorganismos, que tenían altas tasas de morbilidad y mortalidad, se pudieran tratar, obteniéndose así un significativo impacto positivo en la salud pública en todo el mundo. 
Cuadro 1. Bacterias aisladas de las muestras corneales e intraoculares

\begin{tabular}{|c|c|c|c|c|}
\hline Gram positivos & $\begin{array}{l}\text { Queratitis } \\
\text { n (\%) }\end{array}$ & $\begin{array}{l}\text { Fluidos } \\
\text { intraoculares } \\
n(\%)\end{array}$ & $\begin{array}{c}\text { Botón } \\
\text { corneal } \\
\mathrm{n}(\%)\end{array}$ & $\begin{array}{l}\text { Total } \\
\text { n (\%) }\end{array}$ \\
\hline $\begin{array}{l}\text { Estafilococos positivos para coagulasa } \\
\text { resistentes a la meticilina }\end{array}$ & $8(10)^{*}$ & $2(12)^{*}$ & $1(100)^{*}$ & $11(11)^{\star \star}$ \\
\hline $\begin{array}{l}\text { Estafilococos negativos para coagulasa } \\
\text { resistentes a la meticilina }\end{array}$ & $30(40)^{*}$ & $9(53)^{*}$ & 0 & $39(40)^{\star *}$ \\
\hline $\begin{array}{l}\text { Estafilococos positivos para coagulasa } \\
\text { sensibles a meticilina }\end{array}$ & $3(4)^{*}$ & $4(24)^{*}$ & 0 & $7(7)^{\star *}$ \\
\hline $\begin{array}{l}\text { Estafilococos negativos para coagulasa } \\
\text { sensibles a la meticilina }\end{array}$ & $17(21)^{*}$ & 0 & 0 & $17(17)^{\star *}$ \\
\hline Micrococcus luteus & $2(2,5)^{*}$ & $1(6)^{*}$ & 0 & $3(3)^{* *}$ \\
\hline Corynebacterium spp. & $9(11)^{*}$ & $1(6)^{*}$ & 0 & $10(10)^{\star *}$ \\
\hline Micrococcus spp. & $1(1)^{*}$ & $0(0)^{*}$ & 0 & $1(1)^{\star *}$ \\
\hline Streptococcus spp., grupo alfa hemolítico & $5(6)^{*}$ & 0 & 0 & $5(5)^{* *}$ \\
\hline Coryneforme spp., aerobio & $4(5)^{*}$ & 0 & 0 & $4(4)^{\star *}$ \\
\hline Bacillus cereus & $1(1)^{*}$ & 0 & 0 & $1(1)^{* *}$ \\
\hline Total Gram positivos & 80 & 17 & 1 & $98(89)^{\star * *}$ \\
\hline Gram negativos & $\begin{array}{l}\text { Queratitis } \\
\text { n (\%) }\end{array}$ & $\begin{array}{l}\text { Fluidos } \\
\text { intraoculares } \\
n(\%)\end{array}$ & $\begin{array}{c}\text { Botón } \\
\text { corneal } \\
\mathrm{n}(\%)\end{array}$ & $\begin{array}{l}\text { Total } \\
\text { n (\%) }\end{array}$ \\
\hline Pseudomonas aeruginosa & $7(64)^{*}$ & 0 & 0 & $7(58)^{\star *}$ \\
\hline Enterobacter spp. & $1(9)^{*}$ & 0 & 0 & $1(8)^{* *}$ \\
\hline Morganella morganni & $2(18)^{*}$ & 0 & 0 & $2(17)^{\star *}$ \\
\hline Klebsiella enterobacter & $1(9)^{*}$ & 0 & 0 & $1(8)^{\star *}$ \\
\hline Haemophilus spp. & 0 & $1(100)^{*}$ & 0 & $1(8)^{\star \star}$ \\
\hline Total Gram negativos & $11(100)$ & $1(100)$ & 0 & $12(11)^{* * *}$ \\
\hline Total bacterias & 91 & 18 & 1 & 110 \\
\hline
\end{tabular}

* Porcentaje con respecto al total de bacterias Gram positivas o Gram negativas procedente de ese sitio anatómico

** Porcentaje con respecto al total de bacterias Gram positivas o Gram negativas

*** Porcentaje con respecto al total de bacterias Gram positivas y Gram negativas

Cuadro 2. Tipo y cantidad de microorganismos aislados de una misma muestra

\begin{tabular}{lr}
\hline Tipo y cantidad de microorganismos aislados & Casos (\%) \\
\hline 1 bacteria & $42(45,7)$ \\
2 bacterias & $15(16,3)$ \\
1 hongo & $4(4,3)$ \\
1 bacteria + 1 hongo & $13(14,1)$ \\
2 bacterias + 1 hongo & $6(6,5)$ \\
1 bacteria + 1 ameba & $8(8,7)$ \\
2 bacterias + 1 hongo + 1 ameba & $3(3,3)$ \\
1 bacteria + 1 hongo + 1 ameba & $1(1,1)$ \\
Total & 92 \\
\hline
\end{tabular}

Cuadro 3. Patrón de sensibilidad y resistencia a antimicrobianos de todas las bacterias

\begin{tabular}{lcccccrr}
\hline & $\begin{array}{c}\text { Imipenem } \\
\mathbf{n}(\%)\end{array}$ & $\begin{array}{c}\text { Moxifloxacina } \\
\mathbf{n}(\%)\end{array}$ & $\begin{array}{c}\text { Gatifloxacina } \\
\mathbf{n}(\%)\end{array}$ & $\begin{array}{c}\text { Levofloxacina } \\
\mathbf{n}(\%)\end{array}$ & $\begin{array}{c}\text { Ciprofloxacina } \\
\mathbf{n}(\%)\end{array}$ & $\begin{array}{c}\text { Tobramicina } \\
\mathbf{n}(\%)\end{array}$ \\
\hline Sensible & $92(91,1)$ & $84(81,5)$ & $95(91,3)$ & $60(64,5)$ & $24(25,8)$ & $3(9,7)$ \\
Sensibilidad intermedia & $8(7,9)$ & $18(17,5)$ & $8(7,7)$ & $19(20,4)$ & $43(46,2)$ & $8(25,8)$ \\
Resistente & $1(1)$ & $1(1)$ & $1(1)$ & $14(15,1)$ & $26(28)$ & $20(64,5)$ \\
Total & 101 & 103 & 104 & 93 & 93 & 31 \\
\hline
\end{tabular}


Cuadro 4. Sensibilidad y resistencia al imipenem

\begin{tabular}{|c|c|c|c|c|}
\hline & \multicolumn{4}{|c|}{ Gram positivos } \\
\hline & $\begin{array}{c}\text { S } \\
\text { n (\%) }\end{array}$ & $\begin{array}{c}\text { SI } \\
\text { n (\%) }\end{array}$ & $\begin{array}{c}\mathbf{R} \\
\mathrm{n}(\%)\end{array}$ & $\begin{array}{l}\text { Total } \\
\text { n (\%) }\end{array}$ \\
\hline Córnea & $64(88,9)^{*}$ & $7(9,7)^{*}$ & $1(1,4)^{*}$ & 72 \\
\hline Humor acuoso o vítreo & $16(100)^{*}$ & $0(0)^{*}$ & $0(0)^{*}$ & 16 \\
\hline Botón corneal & $1(100)^{*}$ & $0(0)^{*}$ & $0(0)^{*}$ & 1 \\
\hline \multirow[t]{3}{*}{ Total Gram positivos } & $81(91,0)^{* *}$ & $7(7,9)^{* *}$ & $1(1,1)^{\star *}$ & $89(88,1)^{* * *}$ \\
\hline & \multicolumn{4}{|c|}{ Gram negativos } \\
\hline & $\begin{array}{c}\text { S } \\
n(\%)\end{array}$ & $\begin{array}{c}\text { SI } \\
\text { n (\%) }\end{array}$ & $\begin{array}{c}\text { R } \\
\text { n (\%) }\end{array}$ & $\begin{array}{l}\text { Total } \\
\text { n (\%) }\end{array}$ \\
\hline Córnea & $11(100)^{*}$ & $0 \quad(0)^{*}$ & $0(0)^{*}$ & 11 \\
\hline Humor acuoso o vítreo & $0(0)^{*}$ & $1(100)^{*}$ & $0(0)^{*}$ & 1 \\
\hline Total Gram negativos & $11(91,7)^{\star *}$ & $1(8,3)^{* *}$ & $0(0)^{* *}$ & $12(11,9)^{\star * *}$ \\
\hline
\end{tabular}

S: sensible; SI: sensibilidad intermedia; R: resistente

* Porcentaje con respecto al total de bacterias Gram positivas o Gram negativas estudiadas para el imipemen procedente de ese sitio anatómico

** Porcentaje con respecto al total de bacterias Gram positivas o Gram negativas estudiadas para el imipemen

*** Porcentaje con respecto al total de bacterias Gram positivas y Gram negativas estudiadas para el imipemen

Cuadro 5. Sensibilidad y resistencia a la moxifloxacina

\begin{tabular}{|c|c|c|c|c|}
\hline & \multicolumn{4}{|c|}{ Gram positivos } \\
\hline & $\begin{array}{c}\text { S } \\
\text { n (\%) }\end{array}$ & $\begin{array}{c}\text { SI } \\
\text { n (\%) }\end{array}$ & $\begin{array}{c}\mathbf{R} \\
\text { n (\%) }\end{array}$ & $\begin{array}{l}\text { Total } \\
\text { n (\%) }\end{array}$ \\
\hline Córnea & $61(84,7)^{*}$ & $11(15,3)^{*}$ & $0(0)^{*}$ & 72 \\
\hline Humor acuoso o vítreo & $17(94,4)^{\star}$ & $1 \quad(5,6)^{*}$ & $0(0)^{*}$ & 18 \\
\hline Botón corneal & $0(0)^{*}$ & $1(100)^{\star}$ & $0(0)^{*}$ & 1 \\
\hline \multirow[t]{3}{*}{ Total Gram positivos } & $78(85,7)^{\star *}$ & $13(14,3)^{* *}$ & $0(0)^{* *}$ & $91(88,3)^{* * *}$ \\
\hline & \multicolumn{4}{|c|}{ Gram negativos } \\
\hline & $\begin{array}{c}\text { S } \\
\text { n (\%) }\end{array}$ & $\begin{array}{c}\text { SI } \\
\text { n (\%) }\end{array}$ & $\begin{array}{c}\mathbf{R} \\
\text { n (\%) }\end{array}$ & $\begin{array}{l}\text { Total } \\
\text { n (\%) }\end{array}$ \\
\hline Córnea & $5(45,5)^{*}$ & $5(45,5)^{*}$ & $1(9,1)^{*}$ & 11 \\
\hline Humor acuoso o vítreo & $1(100)^{*}$ & $0(0)^{*}$ & $0(0)^{*} \ldots$ & 1 \\
\hline Total Gram negativos & $6(50)^{* *}$ & $5(41,7)^{\star *}$ & $1(8,3)^{\star *}$ & $12(11,7)^{\star * *}$ \\
\hline
\end{tabular}

S: sensible; SI: sensibilidad intermedia; R: resistente

* Porcentaje con respecto al total de bacterias Gram positivas o Gram negativas estudiadas para la moxifloxacina procedente de ese sitio anatómico

** Porcentaje con respecto al total de bacterias Gram positivas o Gram negativas estudiadas para la moxifloxacina

*** Porcentaje con respecto al total de bacterias Gram positivas y Gram negativas estudiadas para la moxifloxacina

Cuadro 6. Sensibilidad y resistencia a la gatifloxacina

\begin{tabular}{|c|c|c|c|c|}
\hline & \multicolumn{4}{|c|}{ Gram positivos } \\
\hline & $\begin{array}{c}\text { S } \\
\text { n (\%) }\end{array}$ & $\begin{array}{c}\text { SI } \\
\text { n (\%) }\end{array}$ & $\begin{array}{c}\mathbf{R} \\
\mathbf{n}(\%)\end{array}$ & $\begin{array}{l}\text { Total } \\
\text { n (\%) }\end{array}$ \\
\hline Córnea & $68 \quad(91,9)^{*}$ & $5(6,8)^{*}$ & $1(1,3)^{*}$ & 74 \\
\hline Humor acuoso o vítreo & $16(94,1)^{\star}$ & $1(5,9)^{*}$ & $0(0)^{*}$ & 17 \\
\hline Botón corneal & $1(100)^{*}$ & $0(0)^{*}$ & $0(0)^{*}$ & 1 \\
\hline \multirow[t]{3}{*}{ Total Gram positivos } & $85(92,4)^{* *}$ & $6(6,5)^{\star \star}$ & $1(1,1)^{\star *}$ & $92(88,5)^{\star \star \star}$ \\
\hline & \multicolumn{4}{|c|}{ Gram negativos } \\
\hline & $\begin{array}{c}\text { S } \\
\text { n (\%) }\end{array}$ & $\begin{array}{c}\text { SI } \\
\text { n (\%) }\end{array}$ & $\begin{array}{c}\mathbf{R} \\
\mathbf{n}(\%)\end{array}$ & $\begin{array}{l}\text { Total } \\
\text { n (\%) }\end{array}$ \\
\hline Córnea & $9(81,8)^{*}$ & $2(18,2)^{*}$ & $0(0)^{*}$ & 11 \\
\hline Humor acuoso o vítreo & $1(100)^{*}$ & $0(0)^{*}$ & $0(0)^{*}$ & 1 \\
\hline Total Gram negativos & $10(83,3)^{\star *}$ & $2(16,7)^{\star *}$ & $0(0)^{\star *}$ & $12(11,5)^{\star \star \star}$ \\
\hline
\end{tabular}

S: sensible; SI: sensibilidad intermedia; R: resistente

* Porcentaje con respecto al total de bacterias Gram positivas o Gram negativas estudiadas para la gatifloxacina procedente de ese sitio anatómico

** Porcentaje con respecto al total de bacterias Gram positivas o Gram negativas estudiadas para la gatifloxacina

*** Porcentaje con respecto al total de bacterias Gram positivas y Gram negativas estudiadas para la gatifloxacina 
Cuadro 7. Sensibilidad y resistencia a la levofloxacina

\begin{tabular}{|c|c|c|c|c|}
\hline & \multicolumn{4}{|c|}{ Gram positivos } \\
\hline & $\begin{array}{c}\text { S } \\
\text { n (\%) }\end{array}$ & $\begin{array}{c}\text { SI } \\
\text { n (\%) }\end{array}$ & $\begin{array}{c}\mathbf{R} \\
\mathbf{n}(\%)\end{array}$ & $\begin{array}{l}\text { Total } \\
\text { n (\%) }\end{array}$ \\
\hline Córnea & $40(61,5)^{\star}$ & $15(23,1)^{*}$ & $10(15,4)^{*}$ & 65 \\
\hline Humor acuoso o vítreo & $13(76,5)^{\star}$ & $1(5,9)^{*}$ & $3(17,6)^{*}$ & 17 \\
\hline Botón corneal & $0(0)^{*}$ & $0(0)^{*}$ & $1(100)^{*}$ & 1 \\
\hline \multirow[t]{3}{*}{ Total Gram positivos } & $53(63,9)^{\star *}$ & $16(19,3)^{\star *}$ & $14(16,9)^{\star *}$ & $83(89,2)^{\star \star \star}$ \\
\hline & \multicolumn{4}{|c|}{ Gram negativos } \\
\hline & $\begin{array}{c}\text { S } \\
\text { n (\%) }\end{array}$ & $\begin{array}{c}\text { SI } \\
\text { n (\%) }\end{array}$ & $\begin{array}{c}\mathbf{R} \\
\mathbf{n}(\%)\end{array}$ & $\begin{array}{l}\text { Total } \\
\text { n (\%) }\end{array}$ \\
\hline Córnea & $6(66,7)^{\star}$ & $3(33,3)^{*}$ & $0(0)^{*}$ & 9 \\
\hline Humor acuoso o vítreo & $1(100)^{*}$ & $0(0)^{*}$ & $0(0)^{*}$ & 1 \\
\hline Total Gram negativos & $7(70)^{\star \star}$ & $3(30)^{\star *}$ & $0(0)^{\star \star}$ & $10(10,8)^{\star \star \star}$ \\
\hline
\end{tabular}

S: sensible; SI: sensibilidad intermedia; R: resistente

* Porcentaje con respecto al total de bacterias Gram positivas o Gram negativas estudiadas para la levofloxacina procedente de ese sitio anatómico

** Porcentaje con respecto al total de bacterias Gram positivas o Gram negativas estudiadas para la levofloxacina

*** Porcentaje con respecto al total de bacterias Gram positivas y Gram negativas estudiadas para la levofloxacina

Cuadro 8. Sensibilidad y resistencia a la ciprofloxacina

\begin{tabular}{|c|c|c|c|c|}
\hline & \multicolumn{4}{|c|}{ Gram positivos } \\
\hline & $\begin{array}{c}\text { S } \\
\text { n (\%) }\end{array}$ & $\begin{array}{c}\text { SI } \\
\text { n (\%) }\end{array}$ & $\begin{array}{c}\mathbf{R} \\
\text { n (\%) }\end{array}$ & $\begin{array}{l}\text { Total } \\
\text { n (\%) }\end{array}$ \\
\hline Córnea & $14(21,5)^{\star}$ & $34(52,3)^{*}$ & $17(26,2)^{*}$ & 65 \\
\hline Humor acuoso o vítreo & $3(18,8)^{*}$ & $7(43,8)^{*}$ & $6(37,5)^{\star}$ & 16 \\
\hline Botón corneal & $0(0)^{*}$ & $0(0)^{*}$ & $1(100)^{*}$ & 1 \\
\hline \multirow[t]{3}{*}{ Total Gram positivos } & $17(20,7)^{\star \star}$ & $41(50)^{\star *}$ & $24(29,3)^{* *}$ & $82(88,2)^{\star \star \star}$ \\
\hline & \multicolumn{4}{|c|}{ Gram negativos } \\
\hline & $\begin{array}{c}\text { S } \\
\text { n (\%) }\end{array}$ & $\begin{array}{c}\text { SI } \\
\text { n (\%) }\end{array}$ & $\begin{array}{c}\mathbf{R} \\
\mathrm{n}(\%)\end{array}$ & $\begin{array}{l}\text { Total } \\
\text { n (\%) }\end{array}$ \\
\hline Córnea & $7(70)^{*}$ & $2(20)^{*}$ & $1(10)^{*}$ & 10 \\
\hline Humor acuoso o vítreo & $0(0)^{*}$ & $0(0)^{\star}$ & $1(100)^{*}$ & 1 \\
\hline Total Gram negativos & $7(63,6)^{\star \star}$ & $2(18,2)^{\star *}$ & $2(18,2)^{\star *}$ & $11(11,8)^{\star \star \star}$ \\
\hline
\end{tabular}

S: sensible; SI: sensibilidad intermedia; R: resistente

* Porcentaje con respecto al total de bacterias Gram positivas o Gram negativas estudiadas para la ciprofloxacina procedente de ese sitio anatómico

** Porcentaje con respecto al total de bacterias Gram positivas o Gram negativas estudiadas para la ciprofloxacina

*** Porcentaje con respecto al total de bacterias Gram positivas y Gram negativas estudiadas para la ciprofloxacina

Cuadro 9. Sensibilidad y resistencia a la tobramicina

\begin{tabular}{|c|c|c|c|c|}
\hline & \multicolumn{4}{|c|}{ Gram positivos } \\
\hline & $\begin{array}{c}\text { S } \\
\text { n (\%) }\end{array}$ & $\begin{array}{c}\text { SI } \\
\text { n (\%) }\end{array}$ & $\begin{array}{c}\mathbf{R} \\
\text { n (\%) }\end{array}$ & $\begin{array}{l}\text { Total } \\
\text { n (\%) }\end{array}$ \\
\hline Córnea & $0(0)^{*}$ & $2(14,3)^{\star}$ & $12(85,7)^{*}$ & 14 \\
\hline Humor acuoso o vítreo & $0(0)^{*}$ & $1(16,7)^{\star}$ & $5(83,3)^{*}$ & 6 \\
\hline \multirow[t]{3}{*}{ Total Gram positivos } & $0(0)^{\star *}$ & $3(15)^{\star \star}$ & $17(85)^{\star \star}$ & $20(64,5)^{\star \star *}$ \\
\hline & \multicolumn{4}{|c|}{ Gram negativos } \\
\hline & $\begin{array}{c}\text { S } \\
\text { n (\%) }\end{array}$ & $\begin{array}{c}\text { SI } \\
\text { n (\%) }\end{array}$ & $\begin{array}{c}\mathbf{R} \\
\text { n (\%) }\end{array}$ & $\begin{array}{l}\text { Total } \\
\text { n (\%) }\end{array}$ \\
\hline Córnea & $3(30)^{*}$ & $5(50)^{*}$ & $2(20)^{*}$ & 10 \\
\hline Humor acuoso o vítreo & $0(0)^{*}$ & $0(0)^{*}$ & $1(100)^{*}$ & 1 \\
\hline Total Gram negativos & $3(27,3)^{\star *}$ & $5(45,5)^{\star \star}$ & $3(27,3)^{\star *}$ & $11(35,5)^{\star \star \star}$ \\
\hline
\end{tabular}

S: sensible; SI: sensibilidad intermedia; R: resistente

* Porcentaje con respecto al total de bacterias Gram positivas o Gram negativas estudiadas para la tobramicina procedente de ese sitio anatómico

** Porcentaje con respecto al total de bacterias Gram positivas o Gram negativas estudiadas para la tobramicina

*** Porcentaje con respecto al total de bacterias Gram positivas y Gram negativas estudiadas para la tobramicina 
Cuadro 10. Sensibilidad y resistencia de las especies bacterianas

\begin{tabular}{|c|c|c|c|c|c|c|c|c|c|c|c|c|}
\hline \multirow[b]{3}{*}{ Microorganismo } & \multicolumn{12}{|c|}{ Antibiótico } \\
\hline & \multicolumn{4}{|c|}{ Imipenem } & \multicolumn{4}{|c|}{ Moxifloxacina } & \multicolumn{4}{|c|}{ Gatifloxacina } \\
\hline & $\begin{array}{c}\text { S } \\
\text { n (\%) }\end{array}$ & $\begin{array}{c}\text { SI } \\
\text { n (\%) }\end{array}$ & $\begin{array}{c}\mathbf{R} \\
\mathbf{n}(\%)\end{array}$ & $\begin{array}{l}\text { Total } \\
\text { n (\%) }\end{array}$ & $\begin{array}{c}\text { S } \\
\text { n (\%) }\end{array}$ & $\begin{array}{c}\text { SI } \\
\text { n (\%) }\end{array}$ & $\begin{array}{c}\mathbf{R} \\
\mathrm{n}(\%)\end{array}$ & $\begin{array}{l}\text { Total } \\
\text { n (\%) }\end{array}$ & $\begin{array}{c}\text { S } \\
\text { n (\%) }\end{array}$ & $\begin{array}{c}\text { SI } \\
\text { n (\%) }\end{array}$ & $\begin{array}{c}\mathbf{R} \\
\mathbf{n}(\%)\end{array}$ & $\begin{array}{l}\text { Total } \\
\text { n (\%) }\end{array}$ \\
\hline $\begin{array}{l}\text { Estafilococos } \\
\text { negativos para } \\
\text { coagulasa sensibles } \\
\text { a la meticilina }\end{array}$ & $16(100)^{*}$ & 0 & 0 & 16 & $14(82)^{*}$ & $3(18)^{*}$ & 0 & 17 & $15(88)^{*}$ & $2(12)^{*}$ & 0 & 17 \\
\hline $\begin{array}{l}\text { Estafilococos } \\
\text { negativos para } \\
\text { coagulasa resistentes } \\
\text { a la meticilina }\end{array}$ & $28(85)^{*}$ & $4(12)^{*}$ & $1(3)^{*}$ & 33 & $28(85)^{*}$ & $5(15)^{\star}$ & 0 & 33 & $32(97)^{\star}$ & $1(3)^{*}$ & 0 & 33 \\
\hline $\begin{array}{l}\text { Estafilococos } \\
\text { positivos para } \\
\text { coagulasa sensibles } \\
\text { a la meticilina }\end{array}$ & $8(10)^{*}$ & 0 & 0 & 8 & $9(100)^{*}$ & 0 & 0 & 9 & $9(100)^{*}$ & 0 & 0 & 9 \\
\hline $\begin{array}{l}\text { Estafilococos } \\
\text { positivos para } \\
\text { coagulasa resistentes } \\
\text { a la meticilina }\end{array}$ & $11(79)^{*}$ & $3(21)^{*}$ & 0 & 14 & $11(79)^{*}$ & $3(21)^{*}$ & 0 & 14 & $13(93)^{*}$ & $1(7)^{*}$ & 0 & 14 \\
\hline $\begin{array}{l}\text { Streptococcus spp., } \\
\text { grupo alfa hemolítico }\end{array}$ & $4(100)^{*}$ & 0 & 0 & 4 & $4(100)^{*}$ & 0 & 0 & 4 & $3(75)^{*}$ & $1(25)^{*}$ & 0 & 4 \\
\hline \multirow[t]{3}{*}{ Pseudomonas aeruginosa } & $7(100)^{*}$ & 0 & 0 & 7 & $4(57)^{*}$ & $3(43)^{*}$ & 0 & 7 & $7(100)^{*}$ & 0 & 0 & 7 \\
\hline & \multicolumn{12}{|c|}{ Antibiótico } \\
\hline & \multicolumn{4}{|c|}{ Levofloxacina } & \multicolumn{4}{|c|}{ Ciprofloxacina } & \multicolumn{4}{|c|}{ Tobramicina } \\
\hline Microorganismo & $\begin{array}{c}\mathrm{S} \\
\mathrm{n}(\%)\end{array}$ & $\begin{array}{c}\text { SI } \\
\text { n (\%) }\end{array}$ & $\begin{array}{c}\mathbf{R} \\
\mathbf{n}(\%)\end{array}$ & $\begin{array}{l}\text { Total } \\
\text { n (\%) }\end{array}$ & $\begin{array}{l}\text { S } \\
\text { n (\%) }\end{array}$ & $\begin{array}{c}\text { SI } \\
\text { n (\%) }\end{array}$ & $\begin{array}{c}\mathbf{R} \\
\mathrm{n}(\%)\end{array}$ & $\begin{array}{l}\text { Total } \\
\text { n (\%) }\end{array}$ & $\begin{array}{c}\text { S } \\
\text { n (\%) }\end{array}$ & $\begin{array}{c}\text { SI } \\
\text { n (\%) }\end{array}$ & $\stackrel{\text { R }}{n}$ & $\begin{array}{l}\text { Total } \\
\text { n (\%) }\end{array}$ \\
\hline $\begin{array}{l}\text { Estafilococos } \\
\text { negativos para } \\
\text { coagulasa sensibles } \\
\text { a la meticilina }\end{array}$ & $11(73)^{*}$ & $1(7)^{*}$ & $3(20)^{*}$ & 15 & $6(43)^{*}$ & $5(36)^{*}$ & $3(21)^{*}$ & 14 & 0 & 0 & $1(100)^{*}$ & 1 \\
\hline $\begin{array}{l}\text { Estafilococos } \\
\text { negativos para } \\
\text { coagulasa resistentes } \\
\text { a la meticilina }\end{array}$ & $15(52)^{*}$ & $7(24)^{*}$ & $7(24)^{*}$ & 29 & $3(9)^{*}$ & $15(47)^{\star}$ & $14(44)^{*}$ & 32 & 0 & 0 & $6(100)^{*}$ & 6 \\
\hline $\begin{array}{l}\text { Estafilococos } \\
\text { positivos para } \\
\text { coagulasa sensibles } \\
\text { a la meticilina }\end{array}$ & $7(88)^{*}$ & $1(12)^{*}$ & 0 & 8 & $4(67)^{*}$ & $2(33)^{*}$ & 0 & 6 & 0 & $2(40)^{*}$ & $3(60)^{*}$ & 5 \\
\hline $\begin{array}{l}\text { Estafilococos } \\
\text { positivos para } \\
\text { coagulasa resistentes } \\
\text { a la meticilina }\end{array}$ & $13(93)^{*}$ & 0 & $1(7)^{\star}$ & 14 & $1(8)^{*}$ & $9(75)^{*}$ & $2(17)^{\star}$ & 12 & 0 & 0 & $1(100)^{*}$ & 1 \\
\hline $\begin{array}{l}\text { Streptococcus spp., } \\
\text { grupo alfa hemolítico }\end{array}$ & $1(33,3)^{*}$ & $1(33,3)^{*}$ & $1(33,3)^{*}$ & 3 & 0 & $2(67)^{*}$ & $1(33)^{*}$ & 3 & 0 & 0 & $1(100)^{*}$ & 1 \\
\hline Pseudomonas aeruginosa & $4(67)^{\star}$ & $2(33)^{\star}$ & 0 & 6 & $4(67)^{*}$ & $2(33)^{*}$ & 0 & 6 & $3(43)^{\star}$ & $3(43)^{*}$ & $1(14)^{*}$ & 7 \\
\hline
\end{tabular}

S: sensible; SI: sensibilidad intermedia; R: resistente

*Porcentaje de bacterias de la clasificación específica con sensibilidad, sensibilidad intermedia o resistencia al antimicrobiano indicado

Sin embargo, en las últimas décadas la resistencia de los microorganismos a los agentes antimicrobianos se ha incrementado; en este sentido, se ha establecido que el principal factor determinante de dicha resistencia es el uso y el abuso de antibióticos, tanto en humanos como en animales $(1,2)$.

Una característica importante de la resistencia a los antimicrobianos es que su tasa varía de manera muy notable al comparar una región con otra (1).
Además, en el campo específico de la oftalmología, se debe tener en cuenta que los protocolos y las concentraciones de los puntos de corte del Clinical Laboratory Standars Institute de los Estados Unidos, empleados para definir la sensibilidad o resistencia de un microorganismo a un antimicrobiano, se basan en las concentraciones séricas que se pueden alcanzar de forma segura luego de una administración sistémica de los antibióticos específicos 
(7). No existen estándares para las concentraciones alcanzadas en el tejido ocular después de una aplicación tópica y, sin embargo, esas definiciones de sensibilidad y resistencia basadas en las concentraciones séricas con antibióticos sistémicos se han empleado rutinariamente en los estudios microbiológicos de muestras oculares.

Después de la aplicación tópica de antibióticos se logran concentraciones muy altas en el fluido lagrimal $y$, dependiendo de su capacidad de difusión a través del epitelio corneal, también se pueden alcanzar niveles elevados en el estroma corneal, mayores que los que se logran en suero. Sin embargo, en la película lagrimal se puede mantener un volumen total de, aproximadamente, $30 \mu \mathrm{l}$ solo por un breve periodo de menos de cinco minutos, ya que ocurre un rápido drenaje a través del conducto lácrimo-nasal (8). Por ello, las altas concentraciones alcanzadas en la lágrima con medicamentos tópicos no deben llevar a la falsa seguridad de que se están sobrepasando sin dificultad las concentraciones inhibitorias mínimas de las bacterias consideradas resistentes, ya que tales niveles pueden ser muy fugaces. No se han hecho estudios sobre el desempeño de los antimicrobianos en esas condiciones específicas, así que la información obtenida de los análisis de sensibilidad a los antimicrobianos basados en los datos de los niveles séricos alcanzados por los antimicrobianos sistémicos es la única disponible como guía para el oftalmólogo.

Un elemento llamativo, que ya tocamos en un estudio publicado anteriormente con muestras tomadas en el año 2007, es el de la naciente resistencia a las nuevas fluoroquinolonas de cuarta generación (5). En ese reporte sobre muestras recogidas en 2007, la resistencia global de las bacterias (tanto Gram positivas como Gram negativas) procedentes de personas con conjuntivitis, queratitis y endoftalmitis fue de 10,2\% a la moxifloxacina y de $6,5 \%$ a la gatifloxacina. Nos llama la atención que en este nuevo estudio, con muestras de córnea y fluidos intraoculares recolectados entre 2011 y 2012, los niveles de resistencia a estos antibióticos fueron menores ( $1 \%$ para los dos antimicrobianos). No tenemos una clara explicación de este fenómeno.

Al hacer una revisión de la literatura científica recientemente publicada, encontramos que existen amplias variaciones geográficas con respecto a las tasas de sensibilidad o resistencia de los patógenos a las diferentes sustancias.
En el norte de la India, Agarwal, et al., reportaron una resistencia en el grupo total de bacterias de muestras oculares tomadas en 2007 de $5,4 \%$ a la moxifloxacina, $8,6 \%$ a la gatifloxacina y $18,1 \%$ a la tobramicina (9).

En muestras de queratitis bacteriana tomadas entre 2003 y 2006 en el Reino Unido, Sueke, et al., reportaron unas tasas mucho menores de resistencia, con excepción de Streptococcus spp., pues las colonias de $P$. aeruginosa tenían una sensibilidad de 99, 100 y $96 \%$ a la ciprofloxacina, moxifloxacina y gentamicina, respectivamente. En cuanto al Staphylococcus aureus, 84, 98 y $96 \%$ de sus colonias fueron sensibles a la ciprofloxacina, moxifloxacina y gentamicina, respectivamente. Con respecto a los estafilococos negativos para coagulasa, 96, 100 y $89 \%$ mostró sensibilidad a la ciprofloxacina, moxifloxacina y gentamicina, respectivamente. En cuanto a Streptococcus spp., 87 y $100 \%$ mostró sensibilidad a ciprofloxacina y a moxifloxacina, respectivamente, pero todos fueron resistentes a la gentamicina (10).

En el estudio Antibiotic Resistance Monitoring in Ocular MicRorganisms (ARMOR) de muestras de infecciones oculares tomadas en 2009 en los Estados Unidos también llamaron la atención los bajos niveles de resistencia a los aminoglucósidos de las cepas sensibles a meticilina: 10,7, 5,7 y 3,3\% de las colonias de $S$. aureus sensibles a meticilina fue resistente a la ciprofloxacina, moxifloxacina y tobramicina, respectivamente. Por otra parte, para las colonias de $S$. aureus resistentes a la meticilina, esos valores fueron muy altos: 79,5 , 65,4 y $52,6 \%$. En cuanto al comportamiento de los estafilococos negativos para coagulasa y sensibles a meticilina, 19,1, 16,2 y 4,4\% fue resistente a la ciprofloxacina, la moxifloxacina y la tobramicina, respectivamente. Por otra parte, $64,5,47,4$ y $21,1 \%$ de los estafilococos negativos para coagulasa y resistentes a la meticilina mostró resistencia a la ciprofloxacina, la moxifloxacina y la tobramicina, respectivamente. No se identificó ningún caso de resistencia de Streptococcus pneumoniae a la moxifloxacina, y aunque los autores indican que no pudieron clasificar las colonias de neumococo de acuerdo con su resistencia por no contar con puntos de corte establecidos por el Clinical and Laboratory Standards Institute, al usar los sugeridos por esa entidad para el 2012 (concentraciones inhibitorias mínimas de $\leq 4 \mu \mathrm{g} / \mathrm{ml}$ para sensible $\mathrm{y} \geq 16 \mu \mathrm{g} / \mathrm{ml}$ para resistente), se encontró que prácticamente en todos los casos, S. pneumoniae presentaba sensibilidad intermedia o resistencia a la tobramicina $(7,11)$. 
El crecimiento de las tasas de resistencia de las bacterias Gram positivas a las fluoroquinolonas, incluidas las de cuarta generación, es un fenómeno claramente identificado en los Estados Unidos. Miller, et al., reportaron que $96,6 \%$ de las colonias de Staphylococcus spp., grupo negativo para coagulasa, recuperado de casos de endoftalmitis entre 1990 y 1994 era sensible a la gatifloxacina y a la moxifloxacina. Para los microorganismos recuperados de casos que consultaron entre los años 2000 y 2004, la sensibilidad disminuyó a $65,4 \%(12)$.

Morrissey, et al., analizaron muestras procedentes de infecciones oculares de varios países de Europa tomadas entre 2001 y 2002. Al analizar todos los patógenos juntos, 5,5\% mostró resistencia a la gatifloxacina, $12,4 \%$ a ciprofloxacina y $24,3 \%$ a gentamicina. Entre los neumococos no encontraron ninguna colonia resistente a la gatifloxacina, $1,4 \%$ fue resistente a la ciprofloxacina y $94,3 \%$ mostró resistencia a la gentamicina. En cuanto a $S$. aureus sensible a la meticilina, los porcentajes de resistencia fueron de 0,8, 2,4 y 1,6\%, respectivamente. Al analizar $S$. aureus resistente a la meticilina se encontró que $57,1 \%$ era resistente a la gatifloxacina, $91,4 \%$, a la ciprofloxacina y $37,1 \%$, a la gentamicina (13).

En el estudio de Steroids for Corneal Ulcers Trial en el sur de la India se encontró que 9,7\% de 350 bacterias Gram positivas era resistente a la moxifloxacina y $83 \%$, a la tobramicina. En cuanto a las bacterias Gram negativas, 32,3\% era resistente a la moxifloxacina y $10,8 \%$, a la tobramicina (14). Recientemente, en Italia, Blanco, et al., estudiaron Staphylococcus spp. de infecciones del tracto respiratorio e infecciones oculares y encontraron que $100 \%$ de las cepas de $S$. aureus resistentes a la meticilina y $58 \%$ de las de Staphylococcus epidermidis resistentes a la meticilina mostró resistencia a la tobramicina, mientras que 75 y $25 \%$, respectivamente, fue resistente a la moxifloxacina (15). En un estudio realizado en México con muestras procedentes de casos de conjuntivitis, úlceras corneales y endoftalmitis tomadas entre 1999 y 2003, se encontró que las colonias de $S$. epidermidis mostraron entre 46 y $63 \%$ de resistencia a la tobramicina y entre 18 y $21 \%$ a la ciprofloxacina (16).

Los estudios procedentes de otras zonas del mundo han encontrado niveles de resistencia a los antimicrobianos mucho más bajos. Constantinou, et al., al analizar todas las cepas (Gram positivas y Gram negativas) procedentes de queratitis bacterianas de Australia encontraron solo 2,8 \% de resistencia a la ciprofloxacina y $1,6 \%$ de resistencia a la tobramicina (17) y, recientemente, en el norte de la India, Sharma, et al., encontraron 4,7 y 2,3\%, respectivamente (18). Al analizar únicamente los microorganismos Gram negativos aislados de personas con queratitis, también el nivel de resistencia reportado por Lichtinger en Canadá fue de solo 1,8\% para la tobramicina y de 2,6 \% para la ciprofloxacina (19).

Estos hallazgos confirman que existen significativas diferencias regionales en las tasas de resistencia de las bacterias, como se evidenció en el estudio multicéntrico del Programa de Vigilancia Antimicrobiana SENTRY, el cual analizó los niveles de resistencia a la tobramicina de las cepas de $P$. aeruginosa obtenidas de diversos sitios del cuerpo en 1999 y encontró que mientras en Canadá era de $5,8 \%$, en los Estados Unidos era de 7,8 \%, en el área del Pacífico de Asia era de 10,1\%, en Europa era de $31,6 \%$ y en Latinoamérica, de $35,8 \%$ (20). Recientemente, ese mismo programa evaluó los patrones de resistencia de bacilos Gram negativos procedentes de Argentina, Brasil, Chile y México (21). En cepas de $P$. aeruginosa se encontraron niveles de resistencia de $27,6 \%$ para el imipenem, 41,2\% para la ciprofloxacina y $34,4 \%$ para la tobramicina. En las de Enterobacter spp. se encontraron valores de 1,3, 21,1 y $25,1 \%$, respectivamente. En las de Klebsiella spp. los valores fueron de 6,2, 41,3 y 40,8 \%, respectivamente. En un estudio realizado en Colombia entre el 2006 y el 2008 , que fue publicado en 2010 , entre 25 y $31 \%$ de las enterobacterias obtenidas de pacientes en salas generales y unidades de cuidados intensivos fue resistente a la ciprofloxacina (22).

Estos datos refuerzan el concepto de que en algunas regiones del mundo (Latinoamérica, Italia y el sur de la India), los niveles de resistencia a ciertos antibióticos (específicamente a la ciprofloxacina y la tobramicina) son mucho mayores que en otras áreas.

La creciente resistencia a las quinolonas, así como la notoria diferencia en cuanto a la resistencia a los aminoglucósidos, genera contradicciones en torno a las conclusiones y recomendaciones de los estudios llevados a cabo en diferentes lugares. Debido a los bajos niveles de resistencia a los aminoglucósidos, algunos investigadores de los Estados Unidos han llegado a sugerir que estos últimos pueden ser una alternativa preferible a las 
quinolonas de cuarta generación. Es el caso de Hsu, et al., quienes encontraron que $95 \%$ de las bacterias Gram positivas encontradas en la flora ocular estudiada era sensible a la gentamicina, mientras que solo 75 y $78 \%$, respectivamente, lo era a la moxifloxacina y a la gatifloxacina (23). Sin embargo, como ya lo indicamos anteriormente, las grandes diferencias regionales impiden generalizar este tipo de recomendaciones de selección de antimicrobianos.

En el presente estudio encontramos que el $0 \%$ de las bacterias Gram positivas procedentes de infecciones corneales o intraoculares mostró resistencia a la moxifloxacina, $1,1 \%$ a la gatifloxacina y $85 \%$ a la tobramicina. De las bacterias Gram negativas, $8,3 \%$ fue resistente a la moxifloxacina, $0 \%$ a la gatifloxacina y $27,3 \%$ a la tobramicina. Aunque nuestros resultados mostraron bajos niveles de resistencia de las bacterias a las fluoroquinolonas de cuarta generación ( $1 \%$ a la moxifloxacina y $1 \%$ a la gatifloxacina), en un estudio realizado en 2007 habíamos encontrado niveles mayores $(10,2 \%$ a la moxifloxacina y $6,5 \%$ a la gatifloxacina). En ese estudio también incluimos muestras procedentes de casos de conjuntivitis.

En teoría, el desarrollo de resistencia por parte de las bacterias a estas sustancias es improbable, pues deben presentarse mutaciones tanto en el gen de la topoisomerasa IIA (usualmente el gen gyrA que codifica la subunidad A de la ADN-girasa) como en el de la topoisomerasa IV (usualmente en el gen parC que codifica la subunidad $\mathrm{C}$ de la enzima). Las mutaciones suelen darse en una región concreta de esos genes que se denomina QRDR (Quinolone Resistance-Determining Region). Sin embargo, la experiencia ha mostrado que estas dos mutaciones pueden concurrir y producir resistencia y, además, existen otros mecanismos de resistencia, como las alteraciones en la permeabilidad de la membrana, que disminuyen la penetración intracelular del fármaco por alteraciones de los genes que codifican los canales de las porinas y la sobreexpresión de bombas de salida, las cuales expulsan de manera activa los antimicrobianos al medio exterior (24).

Se ha detectado que la exposición repetida a antibióticos tópicos genera resistencia en las bacterias presentes en la conjuntiva. Dave, et al., encontraron que luego de cuatro tratamientos consecutivos con antibióticos tópicos (azitromicina, gatifloxacina, moxifloxacina u ofloxacina), se encontró resistencia a tres o más antibióticos en $69 \%$ de las cepas de $S$. epidermidis en los ojos no tratados, mientras que en los ojos que recibieron el antibiótico tópico el porcentaje fue de $90 \%$. El $71 \%$ de estas bacterias en los ojos tratados fue resistente a cinco o más antibióticos (25). Además, los autores encontraron que la aplicación repetida de macrólidos o fluoroquinolonas tópicas incrementó el porcentaje de $S$. epidermidis en la flora ocular (26).

En conclusión, la presencia de resistencia a las fluoroquinolonas de cuarta generación en las infecciones oculares es una realidad, $y$, aunque encontramos que en este momento es baja en nuestro medio, muy probablemente se convertirá en un problema creciente. Consideramos que debe evaluarse la inclusión de nuevos antibióticos en el arsenal terapéutico disponible para uso tópico en oftalmología; algunos de dichos antibióticos ya están disponibles en presentaciones oftálmicas en otras partes del mundo y otros todavía no se encuentran en forma de colirio como el imipenem, el meropenem, la besifloxacina, la tigeciclina y la linezolida (10). De igual manera, se deben estudiar más detalladamente las interacciones y posibles sinergias de los diferentes antimicrobianos (27). En nuestro medio, los niveles de resistencia a la tobramicina que se encuentran en los agentes etiológicos de las queratitis e infecciones intraoculares son inaceptablemente altos, por lo que no podemos recomendarlos ni para la profilaxis ni para el tratamiento de infecciones oculares.

\section{Conflicto de intereses}

Ninguno de los autores tiene relación alguna con los equipos o sustancias mencionados en este artículo que pueda generar un conflicto de intereses.

\section{Financiación}

Este trabajo no recibió financiación de ninguna entidad pública o privada.

\section{Referencias}

1. Yagupsky P. Selection of antibiotic-resistant pathogens in the community. Pediatr Infect Dis J. 2006;25:974-6. http:// dx.doi.org/10.1097/01.inf.0000239270.33190.71

2. Beceiro A, Tomás M, Bou G. Antimicrobial resistance and virulence: A successful or deleterious association in the bacterial world? Clin Microbiol Rev. 2013;26:185-230. http:// dx.doi.org/10.1128/CMR.00059-12

3. Lichtinger A, Yeung SN, Kim P, Amiran MD, Lovieno A, Elbaz U, et al. Shifting trends in bacterial keratitis in Toronto: An 11-year review. Ophthalmology. 2012;119:178590. http://dx.doi.org/10.1016/j.ophtha.2012.03.031

4. Chawla B, Agarwal P, Tandon R, Titiyal JS, Sharma N, Agarwal $\mathrm{T}$, et al. In vitro susceptibility of bacterial keratitis 
isolates to fourth-generation fluoroquinolones. Eur $\mathrm{J}$ Ophthalmol. 2010;20:300-5.

5. Wong CA, Galvis V, Tello A, Villareal D, Rey JJ. Susceptibilidad antibiótica in vitro a fluoroquinolonas. Arch Soc Esp Oftalmol. 2012;87:72-8. http://dx.doi.org/10.1016/j. oftal.2011.06.023

6. Hsu HY, Lind JT, Tseng L, Miller D. Ocular flora and their antibiotic resistance patterns in the midwest: A prospective study of patients undergoing cataract surgery. Am J Ophthalmol. 2013;155:36-44. http://dx.doi.org/10.1016/j.ajo. 2012.06.024

7. Clinical and Laboratory Standards Institute. Performance Standards for Antimicrobial Susceptibility Testing; TwentySecond Informational Supplement. Document M100-S22. Wayne: CLSI; 2012.

8. Friedlaender MH, Breshears D, Amoozgar B, Sheardown $\mathbf{H}$, Senchyna $\mathbf{M}$. The dilution of benzalkonium chloride (BAK) in the tear film. Adv Ther. 2006;23:835-841. http://dx. doi.org/10.1007/BF02850204

9. Agarwal T, Jhanji V, Satpathy G, Nayak N, Chawla B, Tandon R, et al. Moxifloxacin resistance: Intrinsic to antibiotic or related to mutation? Optom Vis Sci. 2012;89:1721-4. http://dx.doi.org/10.1097/OPX.0b013e31827717d4

10. Sueke H, Kaye S, Neal T, Murphy C, Hall A, Whittaker D, et al. Minimum inhibitory concentrations of standard and novel antimicrobials for isolates from bacterial keratitis. Invest Ophthalmol Vis Sci. 2010;51:2519-24. http://dx.doi. org/10.1167/iovs.09-4638

11. Haas W, Pillar CM, Torres M, Morris TW, Sahm DF. Monitoring antibiotic resistance in ocular microorganisms: Results from the Antibiotic Resistance Monitoring in Ocular micRorganisms (ARMOR) 2009 surveillance study. Am J Ophthalmol. 2011;152:567-74. http://dx.doi.org/10.1016/j.ajo. 2011.03.010

12. Miller D, Flynn PM, Scott IU, Alfonso EC, Flynn HW Jr. In vitro fluoroquinolone resistance in staphylococcal endophthalmitis isolates. Arch Ophthalmol. 2006;124:47983. http://dx.doi.org/10.1001/archopht.124.4.479

13. Morrissey I, Burnett R, Viljoen L, Robbins M. Surveillance of the susceptibility of ocular bacterial pathogens to the fluoroquinolone gatifloxacin and other antimicrobials in Europe during 2001/2002. J Infect. 2004;49:109-14.

14. Oldenburg $\mathbf{C E}$, Lalitha $\mathbf{P}$, Srinivasan $\mathbf{M}$, Manikandan $\mathbf{P}$, Bharathi MJ, Rajaraman R, et al. Moxifloxacin susceptibility mediates the relationship between causative organism and clinical outcome in bacterial keratitis. Invest Ophthalmol Vis Sci. 2013 28;54:1522-6. http://dx.doi.org/10.1167/iovs.1211246

15. Blanco AR, Sudano Roccaro A, Spoto CG, Papa V. Susceptibility of methicillin-resistant staphylococci clinical isolates to netilmicin and other antibiotics commonly used in ophthalmic therapy. Curr Eye Res. 2013;38:811-6. http:// dx.doi.org/10.3109/02713683.2013.780624

16. Juárez-Verdayes MA, Reyes-López MA, Cancino-Díaz ME, Muñoz-Salas S, Rodríguez-Martínez S, de la Serna $\mathbf{F J}$, et al. Isolation, vancomycin resistance and biofilm production of Staphylococcus epidermidis from patients with conjunctivitis, corneal ulcers, and endophthalmitis. Rev Latinoam Microbiol. 2006;48:238-46.

17. Constantinou M, Daniell M, Snibson GR, Vu HT, Taylor HR. Clinical efficacy of moxifloxacin in the treatment of bacterial keratitis: A randomized clinical trial. Ophthalmology. 2007;114:1622-9.

18. Sharma N, Goel M, Bansal S, Agarwal P, Titiyal JS, Upadhyaya AD, et al. Evaluation of moxifloxacin $0.5 \%$ in treatment of nonperforated bacterial corneal ulcers: A randomized controlled trial. Ophthalmology. 2013;120:1173-8. http://dx.doi.org/S0161-6420(12)01092-5.10.1016/j.ophtha. 2012.11.013

19. Lichtinger A, Yeung SN, Kim P, Amiran MD, Lovieno A, Elbaz U, et al. Shifting trends in bacterial keratitis in Toronto: An 11-year review. Ophthalmology. 2012;119:178590. http://dx.doi.org/10.1016/j.ophtha.2012.03.031

20. Gales AC, Jones RN, Turnidge J, Rennie R, Ramphal R. Characterization of Pseudomonas aeruginosa isolates: Occurrence rates, antimicrobial susceptibility patterns, and molecular typing in the global SENTRY Antimicrobial Surveillance Program, 1997-1999. Clin Infect Dis. 2001;32 (Suppl. 2):S146-55. http://dx.doi.org/10.1086/320186

21. Gales AC, Castanheira M, Jones RN, Sader HS. Antimicrobial resistance among Gram-negative bacilli isolated from Latin America: Results from SENTRY Antimicrobial Surveillance Program (Latin America, 20082010). Diagn Microbiol Infect Dis. 2012;73:354-60. http:// dx.doi.org/10.1016/j.diagmicrobio.2012.04.007

22. Briceño DF, Correa A, Valencia C, Torres JA, Pacheco $\mathbf{R}$, Montealegre MC, et al. Actualización de la resistencia a antimicrobianos de bacilos Gram negativos aislados en hospitales de nivel III de Colombia: años 2006, 2007 y 2008. Biomedica. 2010;30:371-81.

23. Hsu HY, Lind JT, Tseng L, Miller D. Ocular flora and their antibiotic resistance patterns in the midwest: A prospective study of patients undergoing cataract surgery. Am J Ophthalmol. 2013;155:36-44. http://dx.doi.org/10.1016/j.ajo. 2012.06.024

24. Alós Jl. Quinolonas. Enferm Infecc Microbiol Clin. 2009; 27:290-7.

25. Dave SB, Toma HS, Kim SJ. Ophthalmic antibiotic use and multidrug-resistant staphylococcus epidermidis: A controlled, longitudinal study. Ophthalmology. 2011;118:2035-40. http:// dx.doi.org/10.1016/j.ophtha.2011.03.017

26. Dave SB, Toma HS, Kim SJ. Changes in ocular flora in eyes exposed to ophthalmic antibiotics. Ophthalmology. 2013;120:937-41.http://dx.doi.org/10.1016/j.ophtha.2012. 11.005

27. Sueke H, Kaye SB, Neal T, Hall A, Tuft S, Parry CM. An in vitro investigation of synergy or antagonism between antimicrobial combinations against isolates from bacterial keratitis. Invest Ophthalmol Vis Sci. 2010;51:4151-5. http://dx. doi.org/10.1167/iovs.09-4839 